\title{
Assessment of Nutritional Status among Early Adolescent Girls (11-14 Years) Attending Government Schools of Visakhapatnam City
}

\author{
Dr.Ganga Bhavani Guduri ${ }^{1}$, Dr.Krishnaveni Avvaru ${ }^{2}$, Dr. S. Appala Naidu ${ }^{3}$ \\ ${ }^{1}$ Assistant Professor, ${ }^{2}$ Professor, ${ }^{3}$ Professor \& HOD, Department of Community Medicine, Andhra Medical \\ College, Visakhapatnam.
}

\begin{abstract}
:
Introduction:Adolescence is a transition period between childhood and adulthood and they constitute $21.4 \%$ of the total population. Adolescent health and nutrition are important issues which have not received the attention it deserves in our country, especially in the context of a girl child. Hence an attempt was made to assess the nutritional status of early adolescents attending government schools.Methodology: A cross sectional descriptive study was conducted among 102 early adolescent girls (11-14 years) attending government school in Visakhapatnam city.Study variables were age, religion, education of the mother, birth order, type of family, BMI, etc.Results:. Nearly $3 / 4^{\text {th }}$ (76.46\%) of study population were in the age group of 12-13 years and their mean age was found to be 12.67 years.Regarding birth order, 38 were first born, 43 were second born, 20 were third born and one was fourth born.Weight of our adolescent girls ranged from $19 \mathrm{kgs}$ to $64 \mathrm{kgs}$ with mean weight of $36.5 \mathrm{kgs}$. Nearly $3 / 4^{\text {th }}(74.5 \%)$ of adolescent girls were having chronic energy deficiency $(B M I<18.5)$. $24.5 \%$ were having normal BMI and one girl was overweight.At the time of study, on clinical examination 10 were found to be pale, 13 were having dental caries and one child was identified as having Bitot's spots.Conclusion:It was found that large proportion of adolescent girls were undernourished. Changes in food habits of adolescents are required for bringing the improvements in the nutrition status of adolescents.
\end{abstract}

Key Words: Adolescent girls, Chronic energy deficiency, Nutritional status

\section{Introduction}

Adolescence is a transition period between childhood and adulthood ${ }^{(1)}$. WHO defines adolescence from age 10-19 years ${ }^{(2)}$. They constitute $21.4 \%$ of the total population ${ }^{(3)}$. Early adolescence among girls is considered more crucial as far as growth and development of reproductive systems including health and nutritional status of individual is concerned. On account of practice of early marriages and potential exposure to greater risk of morbidity and mortality adolescent girls constitute a vulnerable group ${ }^{(4)}$. During the phase of rapid growth the adolescents are at a high risk of developing malnutrition. It is common among adolescents from poor socioeconomic status and from rural and urban slum areas ${ }^{(4)}$.

Adolescent health and nutrition are important issues which have not received the attention it deserves in our country, especially in the context of a girl child. Hence an attempt was made to assess the nutritional status of early adolescents attending government schools.

\section{Methodology}

A cross sectional descriptive study was conducted among early adolescent girls (11-14 years) attending government school in Visakhapatnam city. All the girls who were in the above age group and physically present at the time of study were included. A prior permission was obtained from the school authorities for the conduct of study. It was conducted in the month of December 2013. Study variables were age, religion, education of the mother, birth order, type of family, BMI, etc. Clinical examination of the students was done to detect the signs of nutritional deficiency i.e.,conjunctival pallor, Bitot spots etc., Data was analysed manually and relevant statistical tests were applied.

\section{Results}

In our study, a total of 102 adolescent girls attending government schools were included. Nearly $3 / 4^{\text {th }}$ (76.46\%) of study population were in the age group of 12-13 years and their mean age was found to be 12.67 years. Almost $78 \%$ were Hindus, $16.6 \%$ were Christians and the rest were Muslims by religion.

Regarding educational status of the mother, $42 \%$ stated that their mothers were illiterates and $1 / 3^{\text {rd }}$ (33\%) had secondary level of education. Among the mothers of the study subjects, 38 were unemployed and 54 were engaged in semi-skilled work like sweeping, domestic help, working in pan shops etc. One mother was a teacher by occupation. 
In our study $55 \%$ attained menarche and the mean age at menarche was 12.23 years. Among those who attained menarche, 37 girls stated that their menstrual cycles were regular.

Regarding birth order, 38 were first born, 43 were second born, 20 were third born and one was fourth born.

Weight of our adolescent girls ranged from $19 \mathrm{kgs}$ to $64 \mathrm{kgs}$ with mean weight of $36.5 \mathrm{kgs}( \pm 7.94)$. Height of study population ranged from $124 \mathrm{cms}$ to $162 \mathrm{cms}$ with mean height of $145 \mathrm{cms}( \pm 8.37)$.

Nearly $3 / 4^{\text {th }}(74.5 \%)$ of adolescent girls were having chronic energy deficiency (BMI < 18.5). Only $25 \%$ were having normal BMI and one girl was overweight. On further analysis it was observed that $63 \%$ (48/76) of them were either second or third born.

At the time of study, on clinical examination 10 were found to be pale, 13 were having dental caries and one child was identified as having Bitot's spots. None of the children were receiving IFA supplementation.

\section{Discussion}

In the present study, malnutrition was found to be very high $(74.5 \%)$ which is of concern among adolescent girls. This finding is in contrast with previous studies where the range is between $24-51.7 \%{ }^{(3)}$. Nearly $10 \%$ of the adolescents had pallor in our study whereas it was $28.45 \%$ in a study done by Dambhare DG on nutritional status and morbidity among school going adolescents in Wardha ${ }^{(3)}$, and 30\% in another study conducted by Vinod Wasmik ${ }^{(5)}$.

Among the study participants, dental caries was observed in $12.75 \%$ of the girls in contrast to a study conducted by Dambhare DG et al where $35.34 \%$ of their study population were having dental caries and it was $27.1 \%$ in another study conducted by Vinod Wasmik ${ }^{(5)}$.

\section{Conclusion}

It was found that large proportion of adolescent girls were undernourished. Changes in food habits of adolescents are required for bringing the improvements in the nutrition status of adolescents.

Table No.1: Distribution of study subjects according to type of family, housing and ration card (N=102)

\begin{tabular}{|l|ll|}
\hline Type of family & n & $(\mathbf{\% )}$ \\
\hline Nuclear & 73 & $(71.56)$ \\
\hline Joint & 7 & $(6.86)$ \\
\hline Three Generation & 14 & $(13.72)$ \\
\hline Others & 8 & $(7.84)$ \\
\hline Type of Housing & & \\
\hline Pucca & 68 & $(66.66)$ \\
\hline Semi pucca & 30 & $(29.41)$ \\
\hline Kutcha & 4 & $(3.92)$ \\
\hline Type of Ration Card & & \\
\hline White & 87 & $(85.29)$ \\
\hline Pink & 3 & $(2.94)$ \\
\hline No card & 6 & $(5.88)$ \\
\hline Not known & 6 & $(5.88)$ \\
\hline
\end{tabular}

Table No.2: Distribution of study population according to number of siblings $(\mathrm{N}=102)$

\begin{tabular}{|l|ll|}
\hline No. of siblings & n & $(\boldsymbol{\%})$ \\
\hline 0 & 2 & $(1.96)$ \\
\hline 1 & 46 & $(45.09)$ \\
\hline 2 & 37 & $(36.27)$ \\
\hline 3 & 17 & $(16.66)$ \\
\hline Total & $\mathbf{1 0 2}$ & $\mathbf{( 1 0 0 )}$ \\
\hline
\end{tabular}

Table No.3: Distribution of study population according to Nutritional deficiencies

\begin{tabular}{|l|ll|}
\hline Nutritional deficiencies & n & $(\mathbf{\%})$ \\
\hline Pallor & 10 & $(9.8)$ \\
\hline Dental caries & 13 & $(12.74)$ \\
\hline Vitamin A deficiency & 1 & $(0.98)$ \\
\hline
\end{tabular}

Table No.4: Distribution of study population according to BMI $(\mathrm{N}=102)$

\begin{tabular}{|l|ll|}
\hline BMI & n & $\mathbf{( \% )}$ \\
\hline Under weight $(<18.5)$ & 76 & $(74.5)$ \\
\hline Normal $(18.5-24.99)$ & 25 & $(24.5)$ \\
\hline Over weight $(\geq 25)$ & 1 & $(0.98)$ \\
\hline Total & $\mathbf{1 0 2}$ & $\mathbf{( 1 0 0 )}$ \\
\hline
\end{tabular}




\section{Bibliography}

[1]. T Raja ratnam and Jyoti S Hallad. Nutritional status of adolescents in Northern Karnataka, India. The Journal of Family Medicine,2012 Jun;58(1):55-67

[2]. VijayalakshmiKathowate, Soumitra Ghosh. Nutritional Status of adolescents in Agrarian crises - affected area of Maharashtra, Indian Journal of Community Medicine,2013 July;38(3):180-183

[3]. Dambhare DG, Bharambe MS, Nutritional status and morbidity, Online Journal of Health and Allied Sciences, 2010Apr-Jun;9(2):13

[4]. P.R. Kokiwar, G.S. Sai Prasad, Letter to the Editor: Anemia among Adolescent girls, Quarterly Journalof IPHA,2007 Oct-Dec, Page No.252.

[5]. Vinod Wasmik, B. Srinivas Rao, Devkinandan Rao ， A study of Health Status of Early Adolescent girls residing in Social Welfare Hostels in Vizianagaram district of Andhra Pradesh state, India. International Journal of Collaborative Research on Internal Medicine and Public Health,2012 January; 4(1): 83

[6]. Das DK, Biswas R. Nutritional Status of Adolescent girls in rural areas of norths 24 Parganas district. West Bengal. Ind J Pub Health. 2005; 49(1): 18-20.

[7]. Maiti S, Ali KM, De D, A comparative study on Nutritional Status of Urban and Rural early adolescent School girls of West Bengal, India. J. Nepal PaediatrScc-2011 September-December;31(3):169-174

[8]. SounyajitMaiti,DebasisDe, KaziManjur Ali. Overweight and obesity among Early adolescent school girls in urban area of West Bengal, India. Prevalence assessment using different reference standards, IntJ Prev Med 2013 September; 4(9): 1070-1074. 